DOI: https://doi.org/10.47405/mjssh.v6i4.765

\begin{tabular}{|c|c|}
\hline 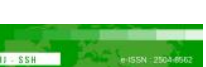 & Malaysian Journal of Social Sciences and Humanities (MJSSH) \\
\hline Malaysian Journa of & Volume 6, Issue 4, April 2021 \\
\hline $\begin{array}{l}\text { Humantes } \\
\text { (MJ-SSH) }\end{array}$ & e-ISSN : 2504-8562 \\
\hline & $\begin{array}{l}\text { Journal home page: } \\
\text { www.msocialsciences.com }\end{array}$ \\
\hline
\end{tabular}

\title{
Integrasi Permainan Media Word Wall dalam Pendidikan Sejarah
}

\author{
Ritchie Len Joon Woei ${ }^{1}$, Soon Singh Bikar ${ }^{1}$, Balan Rathakrishnan' ${ }^{1}$, Zulfikar Rabe ${ }^{1}$ \\ ${ }^{1}$ Fakulti Psikologi dan Pendidikan, Universiti Malaysia Sabah (UMS) \\ Correspondence: Soon Singh Bikar (soonbs@ums.edu.my)
}

\begin{abstract}
Abstrak
Trend terbaru menunjukkan bilangan murid yang lulus mata pelajaran Sejarah di peringkat sekolah menengah semakin menurun. Antara punca yang dikenal pasti ialah Sejarah merupakan mata pelajaran yang amat membosankan dan susah untuk dipelajari kerana terdapat pelbagai fakta yang perlu dihafal. Oleh itu, kajian ini dijalankan untuk menilai kesan pengintegrasian permainan media Word wall terhadap minat, motivasi dan pencapaian murid sekolah menengah dalam mata pelajaran Sejarah. Kaedah kajian kualitatif telah digunakan untuk mengumpul data kajian. 20 orang murid yang sering gagal dalam mata pelajaran Sejarah Tingkatan 4 telah dipilih dengan menggunakan kaedah persampelan tujuan. Empat sesi pemerhatian telah dilakukan semasa aktiviti pembelajaran dan pemudahcaaan $(\mathrm{PdPc})$ berlangsung dalam kelas dan temu bual separa berstruktur telah dijalankan selepas empat minggu menjalankan aktiviti PdPc. Analisa data temu bual menunjukkan murid sekolah menengah mempunyai persepsi yang amat positif terhadap penggunaan permainan Word wall dalam pendidikan Sejarah. Di samping itu, kajian ini juga menunjukkan bahawa penggunaan permainan ini dalam PdPC Sejarah turut mengubah minat dan sikap murid untuk belajar mata pelajaran Sejarah yang amat sinonim sebagai mata pelajaran membosankan dalam kalangan murid sekolah. Aplikasi permainan ini juga berjaya meningkat motivasi intrinsik murid untuk belajar Sejarah. Implikasi kajian ini menunjukkan bahawa permainan Word wall merupakan salah satu permainan teknologi alternatif yang dapat digunakan oleh guru untuk diintegrasikan dalam aktiviti PdPC agar dapat meningkatkan motivasi dan pencapaian Sejarah di sekolah.
\end{abstract}

Kata kunci: word wall, pendidikan sejarah, minat, sikap, motivasi intrinsik

\section{Integration of Word Wall Games in History Education}

\begin{abstract}
The latest trend shows that the number of students passing History subjects at the secondary school level is declining. Among the causes identified is that History is a very boring subject and difficult to learn because there are various facts that need to be memorized. Therefore, this study was conducted to evaluate the impact of Word wall media game integration on the interest, motivation and achievement of high school students in learning History. Qualitative research methods were used to collect research data. 15 students who often failed in the subject of Form 4 History were selected using the method of purpose sampling. Semi -structured interviews were conducted after four weeks of conducting teaching and learning activities. Analysis of interview data showed that high school students had a very positive perception of the use of Word wall games in History education. In addition, this study also shows that the use of this game in learning History also changes the interest and attitude of students to study the subject of History which is very synonymous as a boring subject among school students. The
\end{abstract}


application of this game also increases the intrinsic motivation of students to study History. The implications of this study indicate that Word wall game is one of the alternative ICT games that can be used by teachers to be integrated in teaching and learning activities to increase motivation and achievement of History in school.

Keywords: word wall, history education, interests, attitudes, intrinsic motivations

\section{Pengenalan}

Pada tahun 1863 kurikulum Sejarah telah diperkenalkan di sekolah-sekolah menengah rendah aliran Inggeris. Kurikulum Sejarah pada ketika itu ditentukan oleh Universiti Cambridge, London. Pihak British juga tidak menekankan kurikulum Sejarah tempatan kerana bimbang akan mengugat kedudukan politik dan ekonomi mereka sebagai penjajah di Tanah Melayu (Samsudin \& Shaharuddin, 2012). Namun begitu, pada tahun 1930 pendidikan Sejarah mula diajar secara berperingkat di sekolah aliran Melayu.

Selepas kemerdekaan kurikulum Sejarah sekolah menengah telah mengalami beberapa siri perubahan. Pada tahun 2017 Kurikulum Standard Sekolah Menengah (KSSM) mula dilaksanakan secara berperingkat untuk menggantikan Kurikulum Bersepadu Sekolah Menengah (KBSM) yang mula diperkenalkan pada tahun 1989. Antara matlamat utama kurikulum baru ini adalah meningkatkan kefahaman mengenai masyarakat, negara Malaysia, dunia ,mewujudkan semangat perpaduan, perasaan kekitaan, kesedaran kebangsaan dan memperkukuh perasaan cinta akan negara. Oleh itu, guru digalakkan untuk menggunakan pedagogi dan pendekatan PDPC yang berpusatkan murid. Selain itu Kementerian Pelajaran Malaysia juga menggalakkan guru mengaplikasikan elemen teknologi dalam pengajaran dan pembelajaran (Kementerian Pelajaran Malaysia, 2017). Namun begitu, masih ramai guru yang mengajar Sejarah amat selesa dengan menggunakan kaedah konvensional (Ahmad \& Jinggan, 2017). Antara faktor yang dikenal pasti adalah kompetensi guru dalam menguasai kemahiran Teknologi dan komunikasi (Mookan, Ahmad \& Othman, 2021) dan kekurangan prasarana teknologi di sekolah (Samsudin \& Shaharuddin, 2020). Fenomena ini telah memberi impak yang besar ke atas minat, motivasi dan pencapaian murid sekolah menengah dalam mata pelajaran Sejarah (Kaviza, 2020).

Laporan analisis keputusan Sijil Pelajaran Malaysia (SPM) Tahun 2019 oleh Lembaga Peperiksaan Kementerian Pendidikan Malaysia menunjukkan Gred purata mata pelajaran (GPMP) peringkat nasional bagi mata pelajaran Sejarah telah merosot sebanyak 0.07 peratus. Antara faktor utama yang dikenal pasti adalah murid tidak berminat dengan mata pelajaran Sejarah yang sinonim sebagai mata pelajaran yang bosan dan sukar untuk dipelajari (Lui \& Ahmad, 2021). Selain itu, Ramlah (2020) pula menyatakan bahawa kelemahan guru yang tidak menguasai kaedah pengajaran dan tidak mengaplikasikan inovasi dalam pengajaran turut memberikan kesan ke atas pencapaian mereka dalam mata pelajaran Sejarah. Keadaan ini menyebabkan hilang minat dan bosan dengan mata pelajaran Sejarah yang seterusnya mempengaruhi pencapaian mereka. Kenyataan ini turut disokong oleh kajian yang telah dijalankan oleh (Ahmad, Rabu, Fatimah 2009; Ramli \& Siti 2020) yang menjelaskan bahawa terdapat perhubungan yang signifikan antara minat dengan motivasi murid untuk belajar dan mendapat pencapaian yang cemerlang dan akademik.

Oleh itu, para sarjana mencadangkan agar guru mengaplikasikan teknologi dan menggunakan kaedah pengajaran yang lebih inovatif dalam mengendalikan pengajaran dan pembelajaran dalam bilik darjah agar dapat mengembalikan minat serta memberi motivasi kepada murid untuk belajar dan seterusnya akan meningkatkan pencapaian akademik murid. Saranan ini telah menggalakkan para penyelidik di luar negara untuk melaksanakan pelbagai kajian untuk mengkaji kesan aplikasi teknologi dan ICT dalam pengajaran ke atas minat, motivasi dan pencapaian akademik murid. Misalnya Koparan (2021) telah menjalankan kajian untuk menguji kesan penggunaan permainan simulasi dalam pengajaran Matematik melaporkan bahawa teknologi simulasi ini berjaya meningkatkan minat untuk belajar Matematik. Aljaraideh (2020) pula melaporkan penggunaan bercerita secara digital memberi impak 
yang lebih besar ke atas motivasi dan pencapaian murid dalam Bahasa Inggeris. Kajian Azor, Asogwa, Ogwu dan Apeh (2020) turut membuktikan bahawa penggunaan Youtube, audio dan video memberi kesan yang amat positif ke atas minat, motivasi dan pencapaian sejarah murid sekolah menengah di Nigeria.

Manakala di Malaysia pula, pelbagai kajian turut dijalankan untuk melihat kesan penggunaan teknologi dan ICT ke atas minat, motivasi, dan pencapaian murid dalam pelbagai mata pelajaran. Misalnya, kajian yang dilakukan oleh Salih (2010), beliau menunjukkan bahawa penggunaan teknologi dalam pengajaran Sains adalah penting dan ia dapat mendorong murid untuk menganalisis isi kandungan dan seterusnya dapat melatih murid untuk berfikir dan menjana idea dalam menyelesaikan sesuatu masalah dalam pembelajaran. Selain itu, Osman (2015) juga mendefinisikan pembelajaran berasaskan permainan merupakan satu platform pembelajaran di mana murid merupakan pemain dan juga merupakan pereka cipta permainan digital dalam mempelajari Kimia. Tambahan lagi, pembelajaran dapat dipertingkatkan apabila proses pembelajaran melibatkan murid sebagai pereka cipta permainan digital. Hasil dapatan kajian menunjukkan bahawa penglibatan murid dalam mereka cipta permainan digital pembelajaran dan dikongsi dengan murid lain bukan sahaja dapat meningkatkan penguasaan murid dalam konsep kimia, malah kemahiran menyelesaikan masalah dan kemahiran abad ke-21 juga dapat dikuasai oleh murid dalam pembelajaran.

Walaupun pelbagai kajian di luar dan dalam negara menunjukkan bahawa penggunaan teknologi dan ICT dalam pengajaran dan pemudah caraan dapat meningkatkan minat, motivasi dan pencapaian akademik murid, penggunaan permainan Word wall jarang digunakan dalam mata pelajaran Sejarah. Oleh itu, kajian ini dijalankan untuk mengkaji pandangan murid dan kesan penggunaan permainan ini ke atas minat, motivasi dan pencapaian murid dalam topik Perjuangan Rakyat ke arah Kemerdekaan Tanah Air.

\section{Sorotan Literatur}

\section{Pengintegrasian ICT, Teknologi dan Minat Belajar}

Ledakan ICT telah mempengaruhi perkembangan masyarakat dan juga pedagogi pengajaran. Arkorful, Barfi dan Aboagye (2021) berpendapat bahawa peranan ICT dalam pengajaran harus diambil kira kerana perkembangannya yang pesat telah memberikan idea baru kepada guru untuk menggunakan pelbagai alat ICT dalam aktiviti pengajaran dan pembelajaran di dalam kelas. Oleh itu pelbagai kajian telah dijalankan untuk melihat kesan penggunaan ICT dan teknologi dalam aktiviti PdPc ke atas minat murid (Sahin \& Yilmaz, 2020). Misalnya kajian Önal dan Önal (2021), Laksita et al. (2020), Zhai, Li \& Chen (2019) menunjukkan bahawa pengintegrasian teknologi dan ICT dalam aktiviti PdPc akan meningkatkan minat murid untuk belajar. Hal ini kerana aktiviti PdPc yang dirancang dengan pengintegrasian elemen teknologi ini meningkat minat dan keinginan untuk meneroka isi murid yang diajar oleh guru. Disamping itu, penggunaan ICT dan teknologi ini akan menggalakkan guru mengamalkan kaedah pedagogi yang berpusatkan murid dan akan mengurangkan kebosanan murid untuk belajar. Kenyataan ini disokong oleh dapatan kajian yang dijalankan oleh Baş dan Baştuğ (2020). Namun begitu, dalam kajian ini pengkaji akan menggunakan permainan Word Wall yang sinonim dengan permainan untuk mengajar bahasa untuk mengkaji impak permainan ini ke atas minat, motivasi dan pencapaian dalam mata pelajaran Sejarah.

\section{Pengintegrasian ICT, Teknologi dan Motivasi}

Pelbagai kajian literatur menunjukkan bahawa pengintegrasian elemen teknologi dan ICT dalam proses PdPc meningkatkan motivasi murid untuk belajar (Aljaraideh, 2020; Afzali \& Izadpanah, 2021; Chen, 2019). Hal ini kerana para sarjana berpendapat bahawa penggunaan teknologi dan ICT dalam aktiviti pengajaran lebih menyeronokkan kerana ia mewujudkan persekitaran pembelajaran yang autentik meningkatkan nilai kolaborasi, interaksi dan autonomi murid dalam proses PdPC. Kenyataan ini disokong oleh Kiuru et al. (2020) yang berpendapat bahawa persekitaran pembelajaran ICT dan teknologi meningkatkan autonomi dan interaksi aktif murid yang seterusnya meningkatkan motivasi 
untuk belajar. Namun begitu, terlalu sedikit perhatian diberikan untuk mengkaji kesan pengintegrasian ICT dan teknologi terhadap motivasi intrinsik murid dan khususnya dalam mata pelajaran Sejarah. Oleh itu, dalam kajian ini pengkaji akan melihat kesan penggunaan permainan Word Wall untuk meningkatkan motivasi intrinsik murid dalam mempelajari Sejarah.

\section{Pengintegrasian ICT,Teknologi dan Pencapaian}

Perubahan pesat dalam teknologi maklumat dan komunikasi telah memberi impak yang besar dalam bidang pendidikan terutama sekali dalam aspek persekitaran bilik darjah tradisional dan kaedah pengajaran. Selari dengan perubahan ini pelbagai alat teknologi baru seperti komputer, tablet, projektor, cakera kilat, telefon bimbit, kamera digital dan perakam video mula diguna secara meluas dalam aktiviti PdPC (Akar, 2020). Fenomena ini telah memberi satu inspirasi kepada penyelidik untuk mengkaji impak penggunaan bahan dan permainan berasaskan teknologi dalam pelbagai aspek dan khusus kepada pencapaian akademik murid sekolah. Misalnya kajian Karakoç et al. (2020), Ismaeel dan Al Mulhim (2021) serta Sahin dan Yilmaz (2020) membuktikan penggunaan permainan berasaskan teknologi amat membantu meningkat pencapaian akademik murid sekolah. Hal ini kerana para sarjana berpendapat bahawa penggunaan teknologi dalam bilik darjah meningkatkan autonomi dan pembelajaran kendiri murid. Di samping pembelajaran yang eksplorasi kendiri dengan menggunakan bahan teknologi meningkatkan keyakinan dan keseronokan dan pemahaman murid dalam sesi PDPC. Kenyataan ini amat disokong oleh dapatan kajian Aljaraideh (2020) yang melaporkan bahawa pengintegrasian elemen teknologi dalam pengajaran akan meningkatkan keseronokan dan pembelajaran kendiri murid. Walau bagaimanapun, tidak ada usaha yang dibuat dalam mana-mana kajian untuk mengkaji kesan penggunaan world wall ke atas pencapaian Sejarah murid di sekolah menengah

\section{Metod Kajian}

Data kajian ini diperoleh dengan menggunakan kaedah penyelidikan kualitatif. Hal ini kerana kaedah kualitatif dapat membantu penyelidik memahami masalah kajian secara mendalam (Singh, Rathakrishnan, Talin, Kiflee, 2018). Data penyelidikan kualitatif diperoleh secara temu bual separa berstruktur, pemerhatian dan analisa dokumen kertas ujian murid.

\section{Sampel Kajian}

Bilangan populasi yang mengambil mata pelajaran Sejarah di sekolah kajian adalah 60 orang murid dan 20 orang murid dari populasi ini gagal dalam mata pelajaran Sejarah di peringkat Penilaian Menengah Rendah dan sebanyak 3 kali ujian berturut-turut di Tingkatan 4. Oleh itu, kaedah persampelan bertujuan telah digunakan untuk memilih 20 orang murid ini sebagai peserta kajian ini.

\section{Kaedah Pengumpulan Data}

\section{Temu bual}

Temu bual dijalankan selepas sahaja empat minggu pengajaran berasaskan media Word wall tamat. Sesi temu ramah ini dijalankan di bilik mesyuarat Pusat Sumber sekolah untuk memastikan tidak terdapat sebarang gangguan luar. Setiap sesi temu ramah ini berlangsung selama 35 hingga 45 minit dan dirakam dengan menggunakan telefon bimbit.

\section{Pemerhatian}

Menurut B. Johnson dan Christensen (2012), pemerhatian adalah kaedah penting untuk mengumpulkan maklumat mengenai tingkah laku murid dalam bilik darjah. Hal ini kerana murid tidak selalu melakukan apa yang mereka katakan. Oleh itu, penyelidik menggunakan kaedah pemerhatian untuk melihat perubahan minat dan motivasi murid semasa guru menggunakan media Word wall dalam PdPc. 
Pada keseluruhan empat pemerhatian telah dibuat oleh penyelidik dalam bilik darjah dan setiap sesi pemerhatian ini berlangsung selama 60 minit. Peranan pemerhati dalam kajian ini adalah sebagai peserta pemerhati kerana kaedah ini membolehkan penyelidik mendapat maklumat balas dan membuat kesimpulan dapatan pemerhatian yang tepat (B. Johnson \& Christensen, 2012). Sesi pemerhatian dirakam video dan penyelidik mencatat semua data pemerhatian dengan menggunakan nota lapangan dan borang pemerhatian.

\section{Analisa Dokumen}

Dalam kajian ini juga penyelidik menggunakan kaedah analisa dokumen untuk mengkaji kesan permainan media Word wall ke atas pencapaian Sejarah murid. Setiap ujian atau penilaian dalam kelas akan digunakan oleh guru semasa proses PdPc akan dikumpulkan dan akan dianalisis oleh penyelidik.

\section{Hasil Kajian}

Dalam kajian ini, kaedah analisis tematik digunakan untuk menganalisis data kualitatif. Sebab utama untuk menggunakan kaedah analisis ini adalah kerana ia sangat fleksibel untuk menggunakan perspektif teori yang berbeza (Grbich, 2012). Rakaman wawancara murid ditranskripsikan secara verbatim. Versi yang ditranskripsikan kemudian diperiksa semula dengan rakaman untuk ketepatan. Selanjutnya, transkripsi diimport ke dalam perisian NVIVO versi 10 untuk analisis. Data yang diimport ke dalam perisian NVIVO kemudian dibaca kembali beberapa kali untuk memastikan pengkaji membiasakan diri dengan data. Seterusnya pengkaji telah membuat kod terbuka. Proses ini membantu penyelidikan menghasilkan pelbagai kod baru dan dikelompokkan dengan persoalan kajian. Proses ini telah menghasilkan empat tema utama, iaitu pandangan, minat, motivasi dan pencapaian murid

\section{Latar belakang responden}

Pada keseluruhan kajian ini melibatkan 20 orang murid Tingkatan 4 di sebuah sekolah menengah di daerah Beaufort, Sabah. Umur murid yang terlibat dengan kajian ini ialah antara 16 hingga 17 tahun, dengan purata usia 16.23 tahun. Sebelas orang murid $(55 \%)$ adalah lelaki dan sembilan orang murid (45\%) adalah perempuan.

\section{Apakah pandangan anda mengenai penggunaan media Word wall dalam pengajaran dan pemudahcaraan Sejarah?}

Analisa data menunjukkan bahawa 19 dari 20 murid yang ditemu bual mempunyai pandangan yang amat positif terhadap pengintegrasian media word wall dalam pengajaran dan pemudahcaraan dalam bilik darjah. Hal ini kerana, dalam pembelajaran berasaskan media word wall ini murid perlu melibatkan diri secara aktif dan boleh menyediakan sendiri segala isi pelajaran dan langkah penyelesaian masalah semasa belajar. Misalnya Responden 10 berpendapat

Sia sangat setuju sekiranya media Word wall ini dipakai dalam pengajaran Sejarah...Ia amat menyeronokkan dan membantu saya dalam menyediakan bahan untuk belajar sendiri.emm guna media Word wall ini juga ndak susah.. senang jak bha.. Kita perlu belajar asas permainan dia sahaja.. Ia sangat seronok.

Pandangan yang sama telah diutarakan oleh Responden 12, 13 dan1 4

Sia amat setuju kalau buli ini ganti media Word wall untuk ajar Sejarah. Melalui media ini kita bukan hanya belajar mata pelajaran Sejarah tapi saya juga diajar untuk berfikir untuk menjawab dan melaksanakan aktiviti dengan baik..Di samping itu, ia memudahkan saya mengingati fakta dan tahun Sejarah dengan mudah sekali. 
DOI: https://doi.org/10.47405/mjssh.v6i4.765

Seterusnya Responden 4 pula menjelaskan bahawa penggunaan media Word wall dalam pengajaran ini telah mengubah sikapnya terhadap mata pelajaran Sejarah. Responden ini berpendapat Sejarah adalah amat susah untuk dipelajari dan amat membosankan kerana terdapat pelbagai peristiwa dan fakta perlu diingati. Namun begitu, responden ini berpendapat dengan menggunakan media Word wall pembelajaran Sejarah menjadi lebih mudah, menarik dan amat menyeronokkan.

Tidak ni... saya anggap Sejarah subjek yang susah dan bosan untuk belajar. Sebab itu, saya gagal banyak kali sudah dalam subjek ini. Tapi dengan guna word wall ni macam seronok pula kan..saya mula tetarik pula untuk guna. Sebab diberikan kebebasan penuh untuk bermain So kalau buli la kan saya mau cikgu cikgu Sejarah pakai bha ini permainan untuk ajar agar Sejarah menjadi mata pelajaran kegemaran ramai untuk belajar.

\section{Adakah anda minat dengan Sejarah?}

Soalan ini dikemukakan kepada murid untuk mengetahui tahap minat murid dengan mata pelajaran Sejarah. Analisa data temu bual menunjukkan 100 peratus responden murid menyatakan mereka tidak minat dengan mata pelajaran Sejarah. Antara sebab yang dinyatakan oleh murid ialah Sejarah merupakan mata pelajaran yang penuh dengan peristiwa dan fakta yang perlu diingati dan dihafal. Oleh itu, mereka gagal dalam setiap ujian yang di adakan. Namun begitu, persepsi dan minat murid terhadap Sejarah berubah apabila guru mula mengintegrasikan permainan media Word wall dalam aktiviti pembelajaran dan pemudahcaraan Sejarah. Misalnya Responden 1 menjelaskan bahawa:

Bagi saya la kan...saya tidak minat subjek ini... Ia merupakan subjek yang bosan bagi saya.. But saya mula-mula macam sudah jatuh hati sama Sejarah apabila guru minta kumpulan saya terlibat dalam permainan Word wall dan menjawab soalansoalan yang disediakan. Saya tidak tau pula boleh guna media Word wall untuk belajar Sejarah...Emm kalau guru sejarah sudah lama gunakan permainan ini untuk ajar Sejarah. Saya pasti tidak akan gagal Sejarah lagi.

Responden 17 turut mengulas :

Oh.. Mula-mula saya tidak minat ini Sejarah... Tiga... kali ujian saya gagal. Susah sangat mau faham dan belajar subjek ini sampai beliau(bapa) saya suruh pigi belajar tuisyen. Tapi sekarang saya sudah mula minat ini subjek. Saya mula minat bila guru suruh kami guna game word wall dalam sesi aktiviti pengajaran..

\section{Adakah penggunaan permainan media Word wall meningkat motivasi dan keseronokan anda untuk belajar Sejarah?}

Analisa data temu ramah bersama murid menunjukkan bahawa 85 peratus menyatakan bahawa mereka tidak bermotivasi dan berasa tidak seronok untuk belajar Sejarah. Oleh itu, pencapaian mereka dalam mata pelajaran ini tidak memuaskan dan dipaksa oleh ibu bapa menghadiri kelas tuisyen tambahan. Misalnya Responden 16 menyatakan:

Ndak bha ni...saya tidak bermotivasi untuk belajar subjek ini... susah sangat mau ingat.. Ujian bulan lalu saya dapat markah lulus sahaja.. mama saya suruh ambil tuisyen untuk dapat markah lebih baik..

Kenyataan ini turut disetujui oleh Responden 9 dan 13, 15 dan 17. Misalya responden 13 menjelaskan

Tidak bha.. subjek ini susah mau faham. Ia baru bha bagi kami cikgu pun guna buku teks sahaja... saya tidak faham sangat.. 
Responden murid yang ditemu bual turut menerangkan bahawa mereka mula bermotivasi dan seronok apabila guru mula menggunakan permainan Word wall yang amat menyeronokkan dan tidak mengantuk. Oleh itu, mereka mula melibatkan diri dalam aktiviti PdPc tanpa dipaksa oleh guru dan secara aktif. Misalnya Responden 7 menerangkan bahawa:

Seperti saya kata tadi... tidak bermotivasi untuk belajar Sejarah. Ndak tau saya kenapa susah mau difahami. Tapi dengan gunakan mainan Word wall jadi siuk pula dan saya mudah ingat fakta sejarah. Mungkin cara main sampil belajar sesuai dengan cara saya belajar kali

Analisa data pemerhatian menunjukkan bahawa hanya 20 peratus murid sahaja melibatkan diri dalam aktiviti PdPC untuk 20 minit pertama dalam aktiviti pengajaran pertama. Oleh itu, guru terpaksa menggunakan denda untuk menggalakkan murid melibatkan diri dalam aktiviti PdPc. Namun begitu, sikap murid mula berubah pada masa pengajaran langkah ketiga. Dalam langkah ini guru mula menggunakan media Word wall untuk mengendalikan aktiviti permainan match up bagi "pengertian kemerdekaan" Pemerhatian penyelidik menunjukkan murid mula melibatkan diri secara aktif dengan tanpa paksaan guru. Dalam pemerhatian kedua, ketiga dan keempat murid mula menunjukkan penglibatan 100 peratus dalam setiap aktiviti PdPc yang dijalankan oleh guru

\section{Sejauh manakah anda bersetuju bahawa penggunaan media Word wall ini telah membantu anda meningkatkan pencapaian Sejarah?}

Soalan ini bertujuan menguji kesan penggunaan media Word wall ke atas pencapaian murid. Pada keseluruhan empat bahan ujian telah disediakan oleh guru untuk menguji pencapaian murid dalam setiap sub topik yang di ajar. Satu ujian yang meliputi ujian soalan dari setiap sub topik yang diajar selama empat minggu juga diberikan kepada murid selepas sahaja tamat semua sesi pengajaran sub topik, Analisa dokumen jawapan dan skor murid dalam latihan 1 adalah memuaskan Hanya 5 orang murid berjaya mendapat markah melebihi 70 peratus dan 15 orang lagi murid berjaya mendapat markah 50 peratus ke atas. Namun begitu, analisa dokumen jawapan dan markah murid dalam aktiviti PdPc minggu kedua menunjukkan hampir 10 orang murid berjaya mendapat markah melebihi 70 peratus. Dalam ujian ketiga dan keempat pula menunjukkan bilangan murid yang mendapat markah melebihi 70 peratus telah meningkat ke 18 orang. Dalam ujian akhir yang diandalkan selepas tamat pengajaran semua topik turut menunjukkan bilangan murid yang mendapat grad A adalah 16 orang dan empat orang murid lagi mendapat gred $\mathrm{B}+$. Analisa dokumen pencapaian murid merumuskan bahawa permainan Word wall berjaya meningkatkan pencapaian murid dalam topik yang diajar

Penyelidik seterusnya menjalankan temu bual bersama murid untuk mendapatkan maklumat sejauh manakah permainan Word wall berjaya meningkatkan pencapaian murid dalam topik yang diajar. Analisa data temu bual menunjukkan bahwa 90 peratus murid berjaya memahami topik yang diajar dengan baik kerana permainan Word wall menyeronokkan, meningkatkan perasaan ingin tahu dan aktiviti pembelajaran berlaku tanpa ada sebarang unsur paksaan. Oleh itu, fakta atau isi pelajaran yang disampaikan mudah difahami oleh murid. Misalnya Responden 2 menyatakan :

Saya rumuskan bahawa permainan word wall telah bantu meningkatkan pencapaian saya dalam topik yang diajar oleh guru. Ini kali la pertama saya lulus Sejarah. Saya rasa sangat gembira. Saya percaya permainan ini menimbulkan keseronokan saya untuk belajar dan mudah ingat isi pelajaran yang disampaikan oleh guru. Saya juga mudah ingat isi pelajaran masa menjawab ujian yang diberikan oleh guru.... tidak bermotivasi untuk belajar Sejarah. Ndak tau saya kenapa susah mau difahami. Tapi dengan gunakan mainan Word wall jadi siuk pula dan saya mudah ingat fakta sejarah. Mungkin cara main sampil belajar sesuai dengan cara saya belajar kali 


\section{Perbincangan Kajian}

Salah satu dapatan utama kajian ini menunjukkan bahawa murid sekolah amat positif terhadap penggunaan permainan word wall dalam aktiviti PdPc Sejarah. Dapatan kajian ini agak sukar untuk dibandingkan dengan kajian lepas kerana tidak tedapat sebarang kajian yang mengaplikasikan permainan word wall dalam pendidikan Sains sosial dan Sejarah. Namun begitu, beberapa kajian yang mengintegrasikan permainan ini dalam PdPC Bahasa elayu dan Inggeris menunjuk murid mempunyai pandang yang amat positif terdapat penggunaan permainan word wall ini. Hal ini kerana penyelidik berpendapat bahawa permainan word wall menggalakkan penglibatan yang aktif murid dalam aktiviti PdPC. Disamping itu, permainan word wall ini juga menggalakkan murid berfikir secara aktif dalam aktiviti permainan dan dapat menyelesaikan masalah yang diberikan oleh guru dalam PdPC. Kenyataan ini disokong oleh dapatan kajian yang dijalankan oleh Elyana dan Rini (2021).

Selain itu, dapatan kajian ini juga menunjukkan bahawa penggunaan word wall dalam PdPc pendidikan Sejarah turut meningkat minat murid untuk belajar Sejarah. Dapatan kajian ini selari dengan hasil kajian yang dijalankan oleh Önal dan Önal (2021); Laksita et al. (2020); Zhai et al. (2019) yang melaporkan bahawa aktiviti PdPc yang dirancang dengan pengintegrasian elemen teknologi ini meningkat minat dan keinginan untuk meneroka isi pelajaran yang diajar oleh guru, Disamping itu penggunaan permainan yang berasaskan teknologi juga akan menggalakkan guru mengamalkan kaedah pedagogi yang berpusatkan murid dan akan mengurangkan kebosanan murid untuk belajar.

Kajian ini juga menunjukkan bahawa permainan word wall dalam PdPc turut meningkatkan motivasi intrinsik murid terhadap mata pelajaran Sejarah. Analisa data temu bual dan pemerhatian menunjukkan murid dengan sendiri melibatkan diri dan mengambil bahagian dalam setiap aktiviti PdPC di dalam kelas kerana berasa amat seronok dan teruja untuk belajar. Keseronokan yang timbul ini telah meningkatkan motivasi intrinsik murid untuk belajar. Kenyataan ini selari dengan dapatan kajian yang dijalankan oleh Kiuru et al. (2020) yang melaporkan bahawa persekitaran pembelajaran berasaskan ICT dan teknologi meningkatkan autonomi dan interaksi aktif murid yang seterusnya meningkatkan motivasi untuk mereka belajar.

Analisa data kajian ini juga menunjukkan bahawa permainan word wall ini berjaya meningkat pencapaian murid dalam topik yang diajar oleh guru. Dapatan kajian ini selari dengan kajian yang dijalankan oleh Karakoç et al. (2020), Ismaeel dan Al Mulhim (2021) serta Sahin dan Yilmaz (2020). Pengkaji berpendapat permainan word wall ini meningkat tingkah laku untuk meneroka isi pelajaran secara kendiri dan meningkatkan keseronokan untuk belajar dalam kalangan murid sekolah. Faktor ini memudahkan murid untuk memahami isi kandungan pelajaran yang diajar oleh guru dalam bilik darjah. Kenyataan ini disokong oleh dapatan kajian yang dijalankan Datu et al. (2021).

\section{Kesimpulan}

Rumusan hasil kajian ini menunjukkan bahawa pengintegrasian permainan Word Wall dalam PdPc Sejarah telah mengubah persepsi dan sikap murid dari negatif ke positif terhadap mata pelajaran ini. Di samping itu, dapatan kajian juga menunjukkan bahawa penggunaan permainan Word Wall dalam PdPC Sejarah turut mengubah minat murid untuk belajar Sejarah yang amat sinonim sebagai mata pelajaran membosankan dalam kalangan murid sekolah. Aplikasi permainan ini juga berjaya meningkat motivasi intrinsik murid untuk belajar Sejarah. Oleh itu, guru sejarah boleh menggunakan permainan ini sebagai salah satu alternatif aktiviti dan bahan PdPc untuk meningkatkan minat, motivasi dan pencapaian murid dalam mata pelajaran Sejarah. Pengkaji juga mencadangkan agar kajian lanjut dalam sekala yang lebih besar dan menggunakan pelbagai kaedah kajian dapat dijalankan untuk mengukuhkan lagi dapatan kajian ini. 


\section{Rujukan}

Afzali, Z., \& Izadpanah, S. (2021). The effect of the flipped classroom model on Iranian English foreign language learners: Engagement and motivation in English language grammar. Cogent Education, 8(1), 1870801.

Ahmad, A., \& Jinggan, N. (2017). Pengaruh kompetensi kemahiran guru dalam pengajaran terhadap pencapaian akademik murid dalam mata pelajaran Sejarah. JuKu: Jurnal Kurikulum \& Pengajaran Asia Pasifik, 3(2), 1-11.

Akar, H. (2020). The effect of smart board use on academic achievement: A meta-analytical and thematic study. International Journal of Education in Mathematics, Science and Technology, 8(3), 261-273.

Aljaraideh, Y. A. (2020). The impact of digital storytelling on academic achievement of sixth grade students in English language and their motivation towards it in Jordan. Turkish Online Journal of Distance Education, 21(1), 73-82.

Arkorful, V., Barfi, K. A., \& Aboagye, I. K. (2021). Integration of information and communication technology in teaching: Initial perspectives of senior high school teachers in Ghana. Education and Information Technologies, 1-17.

Baş, G., \& Baştuğ, M. (2020). Teaching-learning conceptions, teaching motivation, and perceptions towards ICT: A research in Turkish public high schools. Education and Information Technologies, 1-19.

Chen, C. H. (2019). The impacts of peer competition-based science gameplay on conceptual knowledge, intrinsic motivation, and learning behavioral patterns. Educational Technology Research and Development, 67(1), 179-198.

Cho, D., \& Chun, B. (2019, May). Virtual Reality as a New Opportunity in Geography Education: From the teachers' perspectives in Korea. In Proceedings of the 2019 5th International Conference on Education and Training Technologies (pp.140-145). ACM.

Datu, J. A. D., McInerney, D. M., Żemojtel-Piotrowska, M., Hitokoto, H., \& Datu, N. D. (2021). Is grittiness next to happiness? Examining the association of triarchic model of grit dimensions with well-being outcomes. Journal of Happiness Studies, 22(2), 981-1009.

Elyana, T., \& Rini, S. (2021). Using word wall for iproving students writing "what are you doing”. MIYAH: Jurnal Studi Islam, 17(01), 16-38.

Heyder, A., Weidinger, A. F., Cimpian, A., \& Steinmayr, R. (2020). Teachers' belief that math requires innate ability predicts lower intrinsic motivation among low-achieving students. Learning and Instruction, 65, 101220.

Ismaeel, D., \& Al Mulhim, E. (2021). The influence of interactive and static infographics on the academic achievement of reflective and impulsive students. Australasian Journal of Educational Technology, 37(1), 147-162.

Karakoç, B., Eryılmaz, K., Özpolat, E. T., \& Yıldırım, İ. (2020). The effect of game-based learning on student achievement: A meta-analysis study. Technology, Knowledge and Learning, 1-16.

Kaviza, M. (2020). Hubungan antara amalan kemahiran 4C dan pencapaian sejarah. Malaysian Journal of Social Sciences and Humanities (MJSSH), 5(12), 405-412.

Kementerian Pelajaran Malaysia (2017). Kurikulum standard sekolah menengah. Kementerian Pelajaran Malaysia: Putrajaya.

Kiuru, N., Spinath, B., Clem, A. L., Eklund, K., Ahonen, T., \& Hirvonen, R. (2020). The dynamics of motivation, emotion, and task performance in simulated achievement situations. Learning and Individual Differences, 80, 101873.

Laksita, G. D., Oktaviani, D., \& Pangestu, A. (2020, April). The effect of android game based learning for student interest in Mathematics Learning. In Proceeding International Conference on Science and Engineering (Vol. 3, pp. 335-338).

Lebar, O. (2017). Penyelidikan Kualitatif: Pengenalan kepada teori dan metode: UPSI, Tanjong Malim, Perak.

Liu, Y., Hau, K. T., Liu, H., Wu, J., Wang, X., \& Zheng, X. (2020). Multiplicative effect of intrinsic and extrinsic motivation on academic performance: A longitudinal study of Chinese students. Journal of personality, 88(3), 584-595. 
Lui, M. Z. M., \& Ahmad, A. (2021). Minat murid terhadap gaya, kaedah pengajaran dan pembelajaran guru dalam pendidikan sejarah. Malaysian Journal of Social Sciences and Humanities (MJSSH), 6(2), 211-221.

Mookan, N., Ahmad, A. R., \& Othman, N. (2021). Pendekatan kepelbagaian pengajaran dari aspek penyampaian, alat bantu mengajar, pedagogi dan peneguhan dalam pembelajaran sejarah. Jurnal Dunia Pendidikan, 3(1), 227-238.

Ni, L. B., Kiflee, D. N. A., Keong, T. C., Talip, R., Singh, S. S. B., Japuni, M. N. M., \& Talin, R. (2019). The effectiveness of video clips to enhance students' achievement and motivation on history learning and facilitation. International Journal of Educational and Pedagogical Sciences. 13(7), 1036-1043.

Samsudin, M., \& Shaharuddin, S. (2012). Pendidikan dan Pengajaran Mata Pelajaran Sejarah di Sekolah di Malaysia. Jebat: Malaysian Journal of History, Politics \& Strategic Studies, 39(2).

Sahin, D., \& Yilmaz, R. M. (2020). The effect of Augmented Reality Technology on middle school students' achievements and attitudes towards science education. Computers \& Education, 144.

Önal, N. T., \& Önal, N. (2021). The effect of augmented reality on the astronomy achievement and interest level of gifted students. Education and Information Technologies, 1-27.

SSB Singh, B Rathakrishnan, S Sharif, R Talin (2016). The effects of geography information system (GIS) based teaching on underachieving students' mastery goal and achievement. Turkish Online Journal of Educational Technology - TOJET, Vol 15(4). ,119-134.

SSB Singh, B Rathakrishnan, R Talin, DNA Kiflee (2018). Pengintegrasian sistem maklumat geografi (GIS) dalam pengajaran dan pembelajaran geografi: Kajian kes di sekolah bestari luar bandar di Sabah. e-Bangi, 14(2).

Zhai, X., Li, M., \& Chen, S. (2019). Examining the uses of student-led, teacher-led, and collaborative functions of mobile technology and their impacts on physics achievement and interest. Journal of Science Education and Technology, 28(4), 310-320.

Zaharin, N. L., Sharif, S., Singh, S., \& Singh, L. B.(2019) Promoting Students' Interest, Attitude and Intrinsic Motivation Towards Learning STEM Through Minimalist Robot Education Programme. International Journal of Service Management and Sustainability, 4(1), 41-66. 